\title{
Agricultural Spray Inspection According to ISO 16122: Part II-Determination of the State of Use and Conservation of Agricultural Sprayers
}

\author{
Alfran Tellechea Martini ${ }^{1}$, José Fernando Schlosser ${ }^{1}$, Emilio Gil ${ }^{2}$, Marcelo Silveira de Farias ${ }^{1}$, \\ Gustavo Oliveira dos Santos ${ }^{1}$, Gilvan Moisés Bertollo ${ }^{1} \&$ Juan Paulo Barbieri ${ }^{1}$ \\ ${ }^{1}$ Department of Rural Engineering, Universidade Federal de Santa Maria, Campus Universitário, Santa Maria, \\ Brazil \\ ${ }^{2}$ Universitat Politècnica de Catalunya, Unidad de Mecanización Agraria, Barcelona, Spain \\ Correspondence: Alfran Tellechea Martini, Department of Rural Engineering, Universidade Federal de Santa \\ Maria, 1000 Ave. Roraima, Campus Universitário, Santa Maria, Brazil. Tel: 55-559-9975-4356. E-mail: \\ alfrantm@gmail.com
}

Received: May 6, 2019

Accepted: June 19, 2019 Online Published: August 15, 2019

doi:10.5539/jas.v11n13p11

URL: https://doi.org/10.5539/jas.v11n13p11

\begin{abstract}
Considering the need to reduce environmental contamination and uplift the effectiveness and quality of pesticide application, this work had the goal to determine the conditions of use and conservation of agricultural sprayers used in the Central and Western border of the state of Rio Grande do Sul, and to identify the most frequent problems in agricultural sprayers. Fifty-six sprayers connected to a three-point hydraulic system and the tractor drawbar were inspected, evaluating the safety and operation items using the methodology described in the Standard ISO 16122. After the evaluations, the collected data were submitted to an exploratory analysis by using descriptive statistics with the use of percentage frequency. Based on the obtained results, it is possible to observe that the most serious problems are mainly related to the safety of the operator and the environment, since $41.07 \%$ of the sprayers did not have the protection of the cardan transmission and $33.93 \%$ did not have the protection of straps and pulleys. In addition, static leaks were present in $46.43 \%$ of the samples and $87.50 \%$ presented dynamic leaks. In $71.43 \%$ of the cases, there was no presence of a clean water reservoir to wash the rigid packagings. Therefore, it is possible to conclude that the state of use and conservation of the inspected sprayers is serious, justifying the need for inspections on agricultural sprayers to become mandatory in Brazil, also requiring government policies for the renewal of these equipments, as well as, the homologation of research centers to conduct tests on agricultural machinery and implements before their commercialization. In addition is also necessary to invest in training of operators by conducting technical courses about the importance of equipment knowledge, available technologies and necessary maintenance, as the level of knowledge is low about the basics of operational safety, maintenance and use of the sprayers which contributes to the high percentages of nonconformity with ISO 16122.
\end{abstract}

Keywords: spraying, agricultural machinery, periodic inspection

\section{Introduction}

Population growth and, consequently, an increased demand for food, make it necessary to obtain higher levels of productivity in agricultural areas. Thus, the search for more efficient techniques, which make it possible to satisfy nutritional needs, productivity increase in already exploited areas and the quality guarantee of food as well as the development and use of the application technology as a way to reduce environmental impacts and improve the control of the biological target, are constant concerns by agricultural producers and companies. Thus, studies concerning the quality of the used machines and the precision of the sprayers are of the utmost importance, given the diversity of the used pesticides and the considerable increase in their use (Martini et al., 2019).

Until then, several works were developed without a specific methodology to evaluate quantitatively and qualitatively the basic items of hydraulic sprayers, in order to determine their conditions of use and maintenance. Therefore, through the analysis of the obtained results, it is possible to observe that there is precarious 
maintenance on most of the existing sprayers, which present inappropriate usage conditions (Casali, 2012). In this regard, the inspections of sprayers may be performed in a mandatory or voluntary way. In both cases, it is necessary to establish standards to perform the activities, their regulation, the frequency of inspections and, for countries belonging to the European Union, it is mandatory to enable the bodies and professionals performing the inspections.

In this sense, in order to standardize the inspection of sprayers, the European countries created the Standard EN 13790, which defined as the field of application the requirements and methods that should be evaluated. The methodology used in this standard consisted in measuring separately and independently the performance of different parts of the sprayers, which allowed the accurate diagnose of defects in the evaluated items, allowing them to be separated into categories (Declercq et al., 2009). According to the same author, categories were divided into (I, II and III), namely: defects that automatically implied rejection (category I); defects resulting in partial rejection, which should be repaired until the next inspection (category II) and defects which were only reported for information purposes, in order to improve the functioning of the sprayer (category III). This standard referred to the conditions of the sprayers, with an emphasis on operational safety, potential risk of environmental contamination and the conditions in which spraying equipments should be to perform the correct application of pesticides.

Based on the Standard EN 13790, the Standard ISO 16122 (2015) was created, which aims at internationally standardizing the methodology used in the inspection of agricultural sprays and at determining, more rigidly when compared to the previous standard, the conducted evaluations. Therefore, this international standard uses equipments with greater precision and reduction of the limits in the differences found in the evaluated items. In addition, it establishes the requirements and methods for the necessary checks on the technical inspections of sprayers, regarding mainly the state of conservation of sprayers, the operational and environmental safety and the ways to optimize the applications, making them more precise. In addition, as described in the Standard ISO 16122, sprayer inspection aims, indirectly, at reducing environmental contamination and efficient control of the biological target as a result of the state of conservation, correct maintenance and use of agricultural sprayers.

The Standard ISO 16122 is composed of four parts referring to the inspection of agricultural and forestry sprayers. The first part refers to sprayers in general. The second part refers to the methodology developed for inspections of sprayers with horizontal bars. The third part mentions the inspection methods to be used on sprayers for the application over tree and shrub crops (turbo atomizers) and the fourth part describes the methodology for the inspection of fixed and semi-mobile sprayers.

Differently from the Brazilian reality, in the countries composing the European Union, both the new equipment and those already used for the application of pesticides must go through the verification of a series of requirements that, when fulfilled, allow its use. For this, quantitative and qualitative evaluations are conducted, as well as functional tests, and must comply with the legal provisions regarding health and risk prevention for the environment and for humans. In this context, Gil et al. (2011) developed the Manual de inspección de equipos de aplicación de fitosanitarios en uso, which was considered as an official guideline for the inspection of sprayers in use in Spain. The main goal in the development of this manual was to allow a better understanding of the patterns, structure and contents to be used in inspecting agricultural sprayers (Gil et al., 2014).

Thus, the goal of the study was to determine the conditions of use and conservation of agricultural sprayers used in the Central and Western Border regions of the state of Rio Grande do Sul, and to identify the most frequent problems in agricultural sprayers.

\section{Materials and Methods}

Conducting this work gave rise to the Projeto de Inspeção de Pulverizadores Agrícolas (PIPA), which was carried out in two regions of the state of Rio Grande do Sul, totaling nine cities. In the central region of the state, the cities of Dona Francisca, Faxinal do Soturno, Ivorá, Restinga Seca, Santa Maria, São João do Polêsine and São Pedro do Sul were included. In the Western Border region, it included the cities of Itaqui and Maçambará.

The methodology described in the Standard ISO 16122 (2015) was used to inspect the sprayers. Considering the existence of the four parts of this Standard, highlight that in this work, parts I and II were used and a questionnaire (Appendix A) was constructed to evaluating items related to protection and safety elements, and operating items in sprayers connected to the three points of the hydraulic system of the tractor and to the drawbar of agricultural tractors.

The presence and operation of protection and safety elements are of utmost importance for the approval of the sprayer during the inspection. In this item the visual evaluation considering the presence and the state of 
conservation of the protection mechanism of the cardan joint, protection of belts and pulleys, protection of the free axis of the pump, container with clean water and presence of leaks.

The leakage assessment was performed in a static and dynamic way through visual analysis of the sprayer, in order to identify the number of leaks throughout the hydraulic circuit (pump, tank, tips, nozzles, mixture compensator, hoses and connections). The identified leaks were divided into: continuous leaks (runoff) and dripping.

As for the operating process, information was collected regarding the theoretical volume $\left(\mathrm{L} \mathrm{ha}^{-1}\right)$ desired by the producer to perform the spraying activity, as well as information regarding the tractor onto which the sprayer was attached. In this item, measures were performed about the actual application volume, as well as the flowmeter flow (when present in the sprayer). In order to measure the real volume, data concerning the average of the collected flow at each spraying tip were used and, through Equation (1), it was verified if the calibration was correct when the maximum difference between the theoretical volume and the actual volume was $\pm 5 \%$.

$$
\mathrm{Q}=\frac{600 \times \mathrm{q}}{\mathrm{V} \times \mathrm{E}}
$$

Where, Q: Application volume $\left(\mathrm{L} \mathrm{ha}^{-1}\right)$; 600: Unit conversion factor; q-Mixture flow per spraying tip $\left(\mathrm{L} \mathrm{min}^{-1}\right)$; $\mathrm{V}$ : Traveling speed of the mechanized set $\left(\mathrm{km} \mathrm{h}^{-1}\right)$; E: Distance $(\mathrm{m})$.

Similarly, the evaluation of the flowmeter (when present) was performed by comparing the flow rate reported by the electronic system of the sprayer (on-board computer) and the total flow of the collected bar, with flowmeters that showed a maximum error of $\pm 5 \%$ compared to the actual flow rate of the spraying bar.

As for the information on the mechanized set, it was considered whether the operating station had a cabin, a platform or a seat, and if it had a rollover protection structure (ROPS). The working speed was also evaluated by using the following Equation (2):

$$
\mathrm{Q}=\frac{180}{\mathrm{~T}}
$$

Where, V: Traveling speed of the mechanized set $\left(\mathrm{km} \mathrm{h}^{-1}\right)$; 180: Unit conversion factor; T: Traveling time of the mechanized set in 50 meters (expressed in seconds).

In the evaluations composing such item, the functioning of the tachometer and the manual accelerator were also considered, as well as the rotation of the power take-off. In order to check the last mentioned item, the tractor's engine was first turned on and the TDP was activated, the engine was then put in working regime (rotation of the engine, which represented $540 \mathrm{rpm}$ in the TDP) and then there was the assessment of the legitimacy of the information available in the tractor tachometer, as well as the determination of the TDP rotation used by operators in agricultural spraying. This measurement was possible by using of a digital Minipa ${ }^{\circledR}$ MDT 2238A tachometer.

In order to determine the conformity level of the inspected sprayers, a PIPA index was created, which, through the values assigned to the points evaluated according to ISO 16122, the sprayers were classified as compliant, partially compliant or not compliant when they reached indices above $90.00 \%$, between 89.00 and $70.00 \%$ and below $69.00 \%$, respectively.

According to Martini (2017), for this classification, the PIPA index was subdivided in three main items: safety, equipment and operation, which represented respectively 40,35 and $25 \%$ of the final classification of each sprayer, being attributed percentage marks to each evaluated sub-item, according to the importance degree highlighted in the methodology used.

This index was developed with the purpose of to make a proposal aiming to standardize the criteria of classification of agricultural sprays to be used in future projects that use ISO 16122 (2015) for inspection of sprayers. It is noted that in this paper the results obtained are regarding safety and operation wich are presented as a second part of the work already published by Martini et al. (2019).

After the evaluations, the collected data were submitted to an exploratory analysis by using descriptive statistics with the use of percentage frequency.

\section{Results and Discussion}

In total, 56 agricultural sprayers were inspected; and sprayers connected to the three points of the tractor represented $55.36 \%$ of the samples, whereas sprayers connected to the tractor's drawbar represented $44.64 \%$ of the total. In Table 1, the evaluation of safety items will be demonstrated. 
Table 1. Evaluation of safety items in agricultural sprayers

\begin{tabular}{lllll}
\hline Item & Good state (\%) & Damaged (\%) & Absent (\%) & Not applicable (\%) \\
\hline Cardan joint protection & 23.21 & 33.93 & 41.07 & 1.79 \\
Strap and pulley protection & 33.93 & 3.57 & 33.93 & 28.57 \\
Protection of the pump free shaft & 23.21 & - & 37.50 & 39.29 \\
Clean water reservoir & 53.57 & 12.50 & 33.93 & - \\
\hline
\end{tabular}

The obtained data show that only $23.21 \%$ of the evaluated machines fulfilled the standard as for the presence and functioning of the protection mechanism of the cardan joint, since of the 56 evaluated sprayers, only $1.79 \%$ did not use a cardan shaft to activate the pump, given the fact that its connection occurs directly in the tractor TDP, thus dismissing the use of protections. However, the most worrying thing is that $41.07 \%$ of the sprayers were being used without the protection of the cardan joint and $33.93 \%$ were working with this damaged safety item, that is, $75.00 \%$ of sprayers present a potential risk to the operator due to absence or damage to cardan joint. Data support Ramos and Cortés (2006), who elucidate that in $45.00 \%$ of the sprayers, the TDP protection was defective due the lack of the maintenance of this protective structure. However, a more critical situation was found by Dornelles et al. (2011), when they obtained the result that in $53.60 \%$ of the inspected equipments, this item was absent.

The safety feature also took into account the presence and functionality of belt and pulley protection, as well as the protection of the pump free shaft. With this, it was possible to observe that in 33.93 and $37.50 \%$, respectively, of the inspected sprayers, these items were absent.

Among the items justifying the higher percentage of sprayers that were not compliant to the Standard ISO 16122, it is possible to highlight the ineffective use or the absence of the cardan joint protection, the protection of belts and pulleys, and the protection of the free pump shaft. Corroborating with Casali (2012), even though it is among the greatest causes of accidents in rural areas, the use of protections for the moving parts in agricultural machines and implements is often ignored by operators.

As for the clean water reservoir for hand washing, in $66.07 \%$ of the sprayers it was present; however, it was working in only $53.57 \%$ of them. Similar data were obtained by Silveira et al. (2006) when concluding that, in $65.00 \%$ of the inspected equipments, the clean water reservoir for hand washing was absent or damaged.

In relation to leaks, 23.21 and $43.75 \%$ of the inspected sprayers presented static and dynamic leaks, respectively (Figure 1).

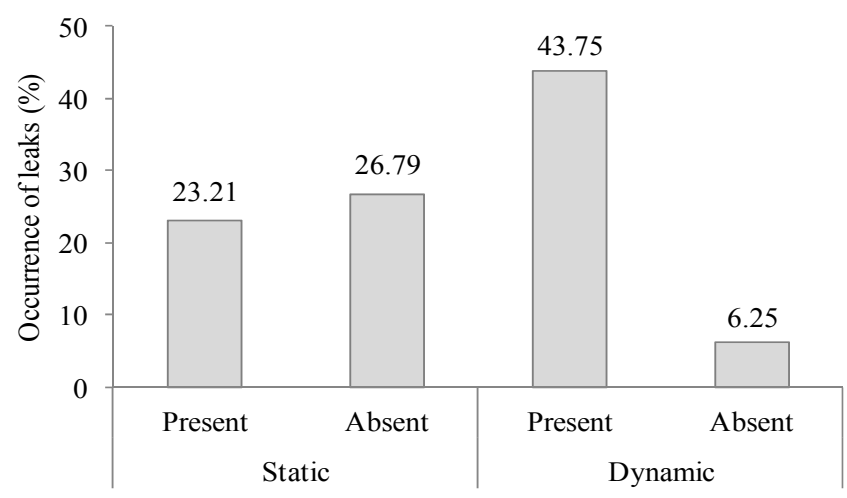

Figure 1. Percentage distribution of the occurrence of static and dynamic leakages

Of the total observed, $35.10 \%$ were considered static leaks. Out of these, $34.66 \%$ were dripping and $0.44 \%$ continuous type leaks. Considering the dripping leaks, it is possible to observe that the greatest losses occurred in the nozzles, representing $76.43 \%$, followed by $12.10,6.37$ and $5.10 \%$ of the drippings for the hydraulic circuit, pump and tank respectively. The high nozzle dripping percentage may be caused by the unsuitable operation or absebce of the anti-drip valve, which according Dornelles (2008) may be relatad to the use of sprayers with low technological index, which its structural design did not provide for the use of this type of valve. 
When analyzing the continuous leaks, it is possible to observe a smaller occurrence compared to dripping, since no losses were observed in the spraying pump and in the hydraulic circuit. However, $50.00 \%$ of the continuous leaks were observed in the deposit and $50.00 \%$ in the nozzles.

Taking into account the dynamic leaks, it can be observed that $64.90 \%$ of the sprayer which presented this kind of leak, $59.16 \%$ were represented by dripping and $5.74 \%$ by continuous leaks.

Similarly to what was observed in static leaks, the highest drip losses $(63.43 \%)$ were observed in the nozzles, followed by the hydraulic circuit, pump and tank, which contributed with $32.46,3.36$ and $0.75 \%$ of the losses, respectively.

When analyzing works on sprayer inspections in Brazil, it is possible to observe that the presence of leaks is one of the most frequent problems in sprayers. According to a study conducted by Alvarenga and Cunha (2010), $61.80 \%$ of the evaluated sprayers presented this type of problem, which is also in accordance with the descriptions made by Machado (2014) and Dornelles et al. (2011), who describe that some kind of leaks are present in 62.00 and $64.30 \%$ of the sprayers, respectively, which are related to the lack of periodic maintenance.

However, Siqueira and Antuniassi (2011) observed that when they carried out an awareness work for operators and owners about the importance of equipment quality, the presence of leaks in the sprayers decreased between the crop years 2006 and 2007. These authors reported that the decrease was about $17.20 \%$ between the mentioned years.

When considering the continuous leaks present in the inspected sprayers, it was observed that $53.85 \%$ of them were in the nozzles, $42.31 \%$ in the hydraulic circuit, and 3.85\% in the tank. For the considered item, no leaks were observed in the pump. According to Siqueira (2009), the main causes of nozzle leaks are due to the inadequate use of the spray tip connection with the nozzle body. Still, according to this author the main problems related to hydraulic circuit leaks are in the misplacement of the line filters in the spray bar. As for Sichocki (2013), the main problem related to the leakage of the deposit is the presence of cracks. In this work, was observed that, on an average, the occurrence of leakages occurred mainly in three places in the sprayer, namely: nozzles, hydraulic circuit and pump; this agrees with the results obtained by Gandolfo (2001), which emphasizes that the highest occurrences were observed in the connection of the cape with the spray tip and in the line filters, representing 58.1 and $9.3 \%$ of the total, respectively.

Analyzing the 56 inspections performed, the sprayer with the largest number of static leaks had 21 drip points. Out of these, $90.50 \%$ of the leaks were observed on the spraying tips because of the non-use of the anti-drip valve. However, when considering the dynamic leakage, this same sprayer analyzed previously had 18 leakage points, $33.30 \%$ of which were due to continuous leakage and $66.60 \%$ to dripping, and out of them, the highest percentage was observed on the spraying tips, which represented $55.50 \%$ of the total. However, the most critical case was observed in one sprayer with 21 leak points. As a result, $76.20 \%$ presented dripping on the tips and in the hydraulic circuit and $19.05 \%$ presented continuous leaks in the hydraulic circuit of the sprayer.

The obtained results indicate that there is a lack of maintenance on these machines, since out of the 2952 evaluated in Germany, only $0.51 \%$ presented leaks (Huyghebaert et al., 1996). This is also different from the results obtained by Langenakens and Pieters (1999) which show that only $16.30 \%$ of the evaluated sprayers presented some type of leakage.

When the item "sprayer operation" was analyzed, the operation position of agricultural tractors and the performance of the activities were evaluated. When analyzing Figure 2, it is possible to notice that $57.14 \%$ of the evaluated tractors were equipped with cabins, allowing the operator to have greater protection and safety during the performed activity. In the other evaluated tractors, $26.79 \%$ presented the a seat-type operative station and $16.07 \%$ were platform-type. However, the item that is worth highlighting is related to the absence of the rollover protection structure (ROPS), which occurred in $30.36 \%$ of the tractors, leaving the operator totally unprotected. 


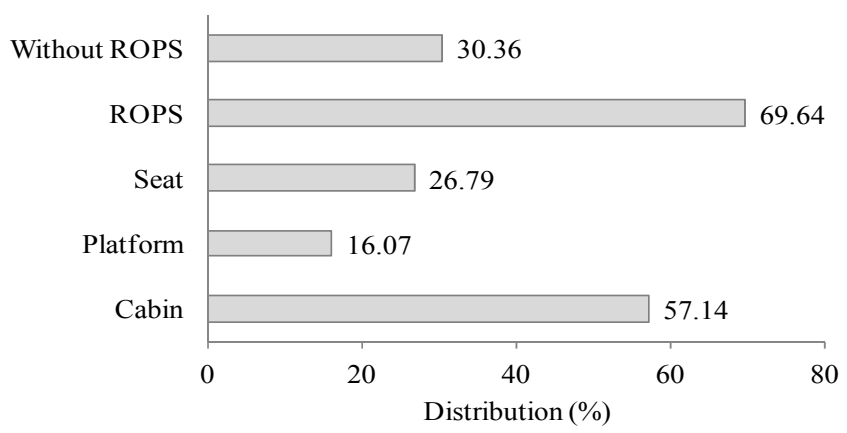

Figure 2. Evaluation of the operation station of tractors that composed the mechanized set (tractor + sprayer)

When considering the tachometer and manual accelerator of the tractors composing the mechanized set, it is possible to observe that only $5.36 \%$ of the cases were not in compliance with the premise for the items at issue.

It is important to emphasize that these items have a direct influence on the quality of the application, since: the tractor tachometer aims at informing the working motor rotation and TDP rotation in order to use its standard rotation $(540 \mathrm{rpm})$, so that the spraying pump performs its maximum effectiveness, keeping the application volume, the return to the mixture tank and the system pressure constant. According to Balestrini (2006), the use of TDP rotation outside the technical recommendation for the pump to reach its highest efficiency can affect the mixture stirring and consequently can cause obstruction of the filters and spray tips. The manual accelerator presents vital importance in the quality of the spraying activity, because its use enables, after selecting the working rotation, it to remain constant, reducing errors in spraying.

Taking into account the importance of the TDP rotation to perform the spraying activities, it is possible to observe that, by confronting the rotation reported on the tachometer with the actual TDP rotation, it was possible to observe that the maximum error found was $7.00 \%$, representing a $38 \mathrm{rpm}$ reduction in the TDP. However, the most worrying thing is related to the use of the engine rotation outside of the manufacturer recommendation, to result in $540 \mathrm{rpm}$ in the power take-off. It is possible to observe in this study that in $69.64 \%$ of the cases, the rotation used in the engine does not match the rotation of $540 \mathrm{rpm}$ in the TDP; it was observed that the most expressive error was the use of a $24.00 \%$ smaller rotation than the one recommended for spraying activity aiming the fuel consumption reduction.

After the evaluation of the items related to the tractor, the theoretical application volume was measured (informed by the producer). In this context, it is worth highlighting that, due to the fact that $23.21 \%$ of the inspected sprayers have a flowmeter, it was necessary to evaluate the accuracy of the flow determination indicated by this device. Therefore, it was observed that in $92.31 \%$ of the sprayers, the flow indicator was approved in relation to the total flow of the bar and, consequently, to the item "application volume"; however only $55.81 \%$ of the other sprayers (without flowmeter) were in accordance with the premise described in the methodology for the item at issue (Table 2).

Table 2. Compliance level of the application volume and flowmeter of the inspected sprayers

\begin{tabular}{lll}
\hline Item & Approved (\%) & Disapproved (\%) \\
\hline Application volume & 55.81 & 44.19 \\
Flowmeter & 92.31 & 7.69 \\
\hline
\end{tabular}

Most of the calibration errors found in the sprayers was related to the absence of the manometer or to the use of these equipments with low accuracy (determination of incorrect values), which is in agreement with what was described by Dornelles et al. (2011), who report that it is necessary to pay more attention to these pressure-determining devices of the hydraulic spray circuit, since their absence may explain the ineffectiveness of many applications.

It is possible to observe that the main calibration error found is directly related to the lack of knowledge about the system pressure, TDP rotation, proper methodology to regulate and calibrate the sprayers, as well as for only using only graduated measuring cups to perform the calibration. The use of the cup may induce a calibration error, as it does not present a standardization of the used scale, which may facilitate an error in reading the scale. 
Siqueira (2009), when evaluating the amplitude and frequency of errors in reading a calibration cup, observed that $51.09 \%$ of the readings presented an error when compared with the actual volume.

Based on the results obtained at the end of the inspections, considering the premise described in the Standard ISO 16122 (2015), it is possible to observe that, out of the 56 evaluated sprayers, only three of them were approved $(5.36 \%)$; however, $26.79 \%$ of the samples were classified as partially compliant and $67.86 \%$ of the sampled total (38 sprayers) were classified as non-compliant (Figure 3).

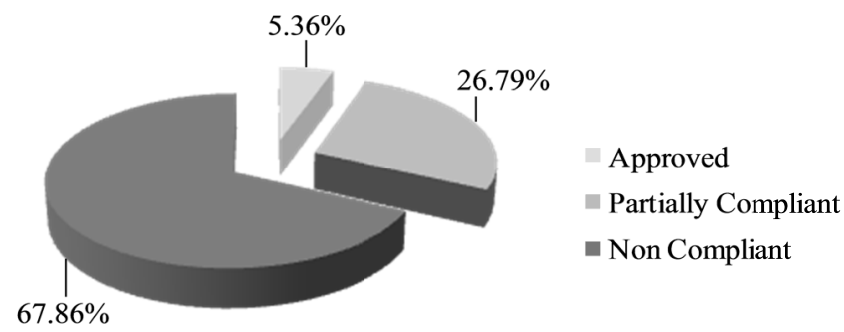

Figure 3. Classification of the inspected sprayers

With the presented results, it is possible to observe that the most serious problems are mainly related to the safety of the operator and the environment. Considering the operator safety, the biggest serious problem are related to the fact that $41.07 \%$ of the sprayers did not have the protection for the cardan shaft, and $33.93 \%$ did not have the protection for straps and pulleys, which which, according to Dornelles (2008), the lack of protection or inadequate protection of moving parts, as well as the approximation of people to these parts, are considered unsafe attitudes and symbolize negligence. According to Debiasi et al. (2004), the unsafe attitudes in the rural environment are responsible for approximately $82.00 \%$ of the accidents involving agricultural machines.

Taking into account the safety of the environment, $46.43 \%$ of the samples presented static leaks and $87.50 \%$ presented dynamic leaks. In $71.43 \%$ of the cases, there was no presence of a clean water reservoir to wash the rigid packagings not meeting to the specified in the ISO 16122 (2015) and raising the percentage of risk to the nvironment.

\section{Conclusion}

After analyzing the obtained results, it is possible to conclude that the state of use and conservation of the inspected sprayers is serious, justifying the need for inspections on agricultural sprayers to become mandatory in Brazil, also requiring government policies for the renewal of these equipments, as well as, the homologation of research centers to conduct tests on agricultural machinery and implements before their commercialization.

In addition is also necessary to invest in training of operators by conducting technical courses about the importance of equipment knowledge, available technologies and necessary maintenance, as the level of knowledge is low about the basics of operational safety, maintenance and use of the sprayers which contributes to the high percentages of nonconformity with ISO 16122.

\section{Acknowledgements}

The authors are grateful to Coordenação de Aperfeiçoamento de Pessoal de Nível Superior (CAPES) and Conselho Nacional de Desenvolvimento Científico e Tecnológico (CNPq) for supporting this study.

\section{References}

Alvarenga, C. B., \& Cunha, J. P. A. R. (2010). Aspectos qualitativos da avaliação de pulverizadores hidráulicos de barra na região de Uberlândia, Minas Gerais. Engenharia Agrícola, 30(3), 555-562. https://doi.org/ $10.1590 / \mathrm{S} 0100-69162010000300019$

Balestrini, L. (2006). Mobile inspection and diagnosis service of sprayers in resistance prevention. Results obtained out of inspections performed by a group producers during the 2004-2005 seanson. Resistant Pest Management Newsletter, 16(1), 5-7. Retrieved from https://whalonlab.msu.edu/wp-content/uploads/2012/ 06/vol.16_no.1final.pdf

Casali, A. L. (2012). Condições de uso de pulverizadores e tratores na região central do Rio Grande do Sul (Master's thesis, Universidade Federal de Santa Maria, Santa Maria, Brazil). Retrieved from https://repositorio.ufsm.br/handle/1/7554 
Debiasi, H., Schlosser, J. F., \& Willes, J. A. (2004). Acidentes de trabalho envolvendo conjuntos tratorizados em propriedades rurais do Rio Grande do Sul, Brasil. Ciência Rural, 34(3), 779-784. https://doi.org/ 10.1590/S0103-84782004000300019

Declercq, J., Huyghebaert, B., \& Nuyttens, D. (2009). An overview of the defects on tested field sprayers in Belgium. $3^{\text {rd }}$ European Workshop on Standardised Procedure for the Inspection of Sprayers, Brno, Czech Republic.

Dornelles, M. E. de Carvalho. (2008). Inspeção técnica de pulverizadores agrícolas no Rio Grande do Sul (Master's thesis, Universidade Federal de Santa Maria, Santa Maria, Brazil). Retrieved from https://repositorio.ufsm.br/handle/1/7508

Dornelles, M. E., Schlosser, J. F., Boller, W., Russini, A., \& Casali, A. L. (2011). Inspeção técnica de tratores e pulverizadores utilizados em pulverização agrícola. Engenharia na Agricultura, 19(1), 36-43. https://doi.org/10.13083/reveng.v19i1.222

Gandolfo, M. A. (2001). Inspeção periódica de pulverizadores agrícolas (Doctoral dissertation, Universidade Estadual Paulista Júlio de Mesquita Filho, Botucatu, Brazil). Retrieved from https://repositorio.unesp.br/ handle/11449/101752

Gil, E., Aguilá, F. G., \& Augustí A. E. (2011). Manual de inspección de equipos de aplicación de fitosanitarios em uso. Ministerio de Medio Ambiente y Medio y Marino, Barcelona, Espanha.

Gil, E., Jiménez, Á., \& Ramos, F. J. G. (2014). Manual for inspection of sprayers in use and PRITEAF, dedicated software for inspection of sprayers: Success tools developed for the inspector's training process in Spain. $5^{\text {th }}$ European Workshop on Standardized Procedure for the Inspection os Sprayers in Europe-SPISE 5, Montpellier, France.

Huyghebaert, B., Mostade, O., Carre, J., \& Debouche, C. (1996). Compulsory inspection of crop sprayers already in use Belgium: Selection of control method. AgEng Madrid, 96, 26, 79-86.

ISO (International Organization for Standardization). (2015). ISO 16122: Agricultural and forestry machinery-Inspection of sprayers in use. Geneva.

Langenakens, J., \& Pieters, M. (1999). Organization and results of the compulsory inspection of sprayer in Belguim. In 7th International Congress for Agriculture, Adana, Turkey.

Machado, T. M. (2014). Inspeção periódica de pulverizadores de barras na região de Guarapuava-PR. Enciclopédia Biosfera, 10(19), 1225-1233.

Martini, A. T. (2017). Inspeção técnica de pulverizadores agrícolas conforme a norma ISO 16122 (Doctoral dissertation, Universidade Federal de Santa Maria, Santa Maria, Brazil). Retrieved from https://repositorio. ufsm.br/handle/1/11349

Martini, A. T., Schlosser, J. F., Gil, E., Farias, M. S., Bertollo, G. M., Oliveira, L. F, V., \& Negri, G. M. (2019). Agricultural spray inspection according to ISO 16122. Journal of Agricultural Science, 11(4), 60-75. https://doi.org/10.5539/jas.v11n4p60

Ramos, F. J. G., \& Cortés, M. V. (2006). Inspección técnica de equipos para la aplicación de fitosanitarios. Vida Rural, 227, 38-42.

Sichocki, D. (2013). Metodologia de inspeção de pulverizadores hidráulicos e hidropneumáticos na região do Alto do Parnaíba-MG (Master's thesis, Universidade Federal de Viçosa, Rio Parnaíba, Brazil). Retrieved from http://www.locus.ufv.br/handle/123456789/2021

Silveira, J. C. M., Gabriel Filho, A., Pereira, J. O., Silva, S. L., \& Modolo, A. J. (2006). Avaliação qualitativa de pulverizadores da região de Cascavel, Estado do Paraná. Acta Scientiarum Agronomy, 28(4), $569-573$. https://doi.org/10.4025/actasciagron.v28i4.901

Siqueira, J. L. (2009). Inspeção periódica de pulverizadores: Análise dos erros de calibração e impacto econômico (Doctoral dissertation, Universidade Estadual Paulista Júlio de Mesquita Filho, Botucatu, Brazil). Retrieved from https://repositorio.unesp.br/handle/11449/101944

Siqueira, J. L., \& Antuniassi, U. R. (2011). Inspeção periódica de pulverizadores nas principais regiões de produção de soja no Brasil. Revista Energia na Agricultura, 26(4), 92-100. https://doi.org/10.17224/ EnergAgric.2011v26n4p92-100 


\section{Appendix A}

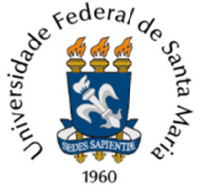

Proprietor:

AGRICULTURAL SPRAYER INSPECTION PROJECT LABORATÓRIO DE AGROTECNOLOGIA-AGROTEC/UFSM

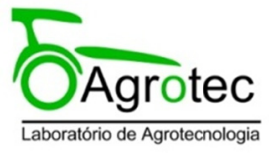

City:

Date: I____ Sprayer $\mathbf{n}^{0}$ :

Brand:

Model: Tank:

(L) Year of manufacture:

Year of acquisition: Sprayed area (ha): GPS point:

Cultivation: Hours/Year: Lenght boom: (m)

Number of sessions:

Nozzle in use: Number of nozzles: Tractor:

Model: Year of manufactura: Hours of use:

1. Elements of protection and safety

Cardan joint protection:

Strap and pulley protection:

Protection of the pump free shaft:

Clean water reservoir:
( ) Good state ( ) Damaged ( ) Absent ( ) Not applicable

( ) Good state ( ) Damaged ( ) Absent ( ) Not applicable

( ) Good state ( ) Damaged ( ) Absent ( ) Not applicable

( ) Good state ( ) Damaged ( ) Absent ( ) Not applicable

2. Leaks in connections or parts-Static (number of points)

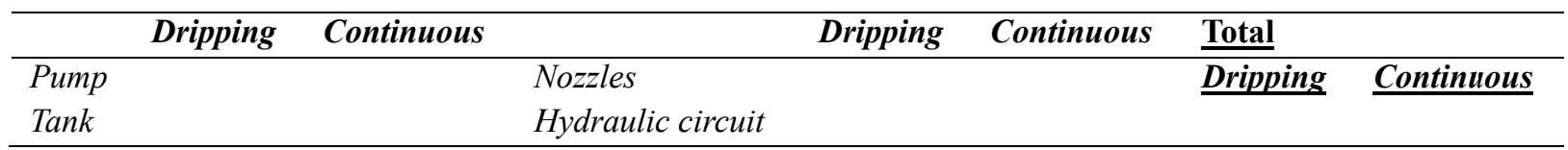

3. Leaks in connections or parts-Dynamic (number of points)

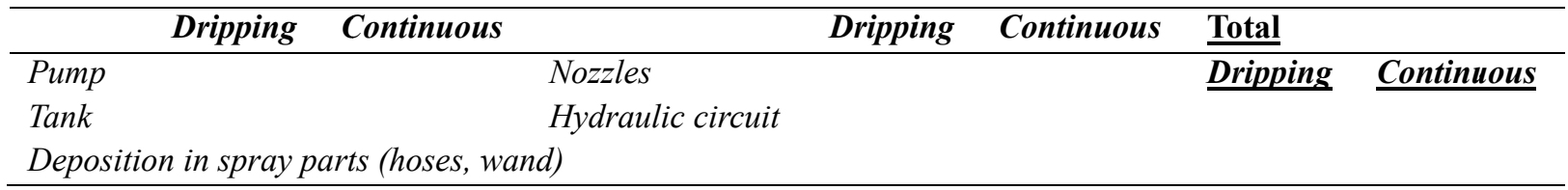

4. Theoretical volume: L/ha Actual volume: L/ha ( ) Approved Disapproved

5. Tractor check:

Operation station: ( ) Cabin ( ) Plataform ( ) Seat ( ) ROPS ( ) Without ROPS

Tachometer: ( ) Good state ( ) Damaged ( ) Absent

Tachometer rotation: _ $\quad \mathrm{rpm}$ TDP rotation: $\_\mathrm{rpm}$

Manual accelerator: ( ) Good state ( ) Damaged ( ) Absent

Operating speed: __ $\mathrm{Km} / \mathrm{h}$ Motor rotation:__ $\mathrm{rpm}$

\section{Copyrights}

Copyright for this article is retained by the author(s), with first publication rights granted to the journal.

This is an open-access article distributed under the terms and conditions of the Creative Commons Attribution license (http://creativecommons.org/licenses/by/4.0/). 